Article

\title{
Cellulose Acetate Phthalate and Antiretroviral Nanoparticle Fabrications for HIV Pre-Exposure Prophylaxis
}

\author{
Subhra Mandal ${ }^{1}$ (D), Karl Khandalavala ${ }^{2}$, Rachel Pham ${ }^{2}$, Patrick Bruck ${ }^{3}$, Marisa Varghese ${ }^{2}$, \\ Andrew Kochvar ${ }^{2}$ (D), Ashley Monaco ${ }^{2}$, Pavan Kumar Prathipati ${ }^{1}$, Christopher Destache ${ }^{1}$ (iD \\ and Annemarie Shibata ${ }^{2, *}$ \\ 1 School of Pharmacy and Health Professions, Creighton University, 2500 California Plaza, \\ Omaha, NE 68178, USA; SubhraMandal@creighton.edu (S.M.); \\ PavanKumarPrathipati@creighton.edu (P.K.P.); ChrisDestache@creighton.edu (C.D.) \\ 2 Department of Biology, Creighton University, 2500 California Plaza, Omaha, NE 68178, USA; \\ karlkhandalavala@creighton.edu (K.K.); Rachelpham@creighton.edu (R.P.); \\ mvarghese@creighton.edu (M.V.); andrewkochvar@creighton.edu (A.K.); \\ ashleymonaco@creighton.edu (A.M.) \\ 3 Dana-Farber Cancer Institute, Harvard University, Boston, MA 02215, USA; \\ PatrickT_Bruck@dfci.harvard.edu \\ * Correspondence: annemarieshibata@creighton.edu; Tel.: +1-402-280-3588
}

Received: 26 July 2017; Accepted: 4 September 2017; Published: 7 September 2017

\begin{abstract}
To adequately reduce new HIV infections, development of highly effective pre-exposure prophylaxis (PrEP) against HIV infection in women is necessary. Cellulose acetate phthalate (CAP) is a $\mathrm{pH}$ sensitive polymer with HIV-1 entry inhibitory properties. Dolutegravir (DTG) is an integrase strand transfer inhibitor with potent antiretroviral activity. DTG delivered in combination with CAP may significantly improve current PrEP against HIV. In the present study, the development of DTG-loaded CAP nanoparticles incorporated in thermosensitive (TMS) gel at vaginal $\mathrm{pH} 4.2$ and seminal fluid pH 7.4 is presented as proof-of-concept for improved PrEP. Water-oil-in-water homogenization was used to fabricate DTG-loaded CAP nanoparticles (DTG-CAP-NPs). Size, polydispersity, and morphological analyses illustrate that DTG-CAP-NPs were smooth and spherical, $\leq 200 \mathrm{~nm}$ in size, and monodispersed with a polydispersity index $\mathrm{PDI} \leq 0.2$. The drug encapsulation $(\mathrm{EE} \%)$ and release profile of DTG-CAP-NPs was determined by HPLC analysis. The EE\% of DTG in DTG-CAP-NPs was evaluated to be $\sim 70 \%$. The thermal sensitivity of the TMS gel was optimized and the $\mathrm{pH}$ dependency was evaluated by rheological analysis. DTG release studies in TMS gel revealed that DTG-CAP-NPs were stable in TMS gel at $\mathrm{pH} 4.2$ while DTG-CAP-NPs in TMS gel at pH 7.4 rapidly release DTG ( $\geq 80 \%$ release within $1 \mathrm{~h}$ ). Cytotoxicity studies using vaginal cell lines revealed that DTG-CAP-NPs were relatively non-cytotoxic at concentration $<1 \mu \mathrm{g} / \mathrm{mL}$. Confocal microscopic studies illustrate that $\geq 98 \%$ cells retained DTG-CAP-NPs intracellularly over seven days. Antiretroviral drug loaded nanocellulose fabrications in TMS gel delivered intravaginally may enhance both microbicidal and antiretroviral drug efficacy and may present a novel option for female PrEP against HIV.
\end{abstract}

Keywords: cellulose acetate phthalate; anti-retroviral; nanoparticles; thermosensitive gel; HIV; pre-exposure prophylaxis

\section{Introduction}

Acquired immune deficiency syndrome (AIDS) caused by HIV infection is one of the insurmountable healthcare problems of the 21st century. Over 35 million people worldwide (1.3 million in the USA) 
are living with HIV-1, and, in 2015, 2.1 million new HIV infections were reported [1,2]. Of those newly infected individuals, $47 \%$ were women and $8 \%$ were children less than 15 years old [1]. Young people between the ages of 15 and 24 accounted for $35 \%$ of all new adult infections, with infection rates of young women in this age group accounting for $20 \%$ of the global sum of HIV infections [1,2]. Greater than $80 \%$ of HIV infections are contracted through sexual transmission and $86 \%$ of female transmission has been attributed to heterosexual intercourse [3,4]. HIV/AIDS remains the leading cause of death for pre-menopausal women worldwide [5]. Given international efforts to reduce the annual global HIV infection rates by $90 \%$ by 2030 [1], highly efficacious therapeutic and preventative HIV therapeutic options must be available to at-risk populations, particularly women.

Initially, natural or semi-synthetic macromolecular HIV-1 entry inhibitors were explored for PrEP of HIV infections. However, clinical trials revealed that macromolecular HIV-1 entry inhibitors alone such as cellulose sulfate, PRO-2000, and carrageenan sulfate do not offer significant protection from HIV infections [6]. Cellulose acetate phthalate (CAP) is an FDA approved low cost pharmaceutical excipient that is widely used for enteric coating of pharmaceutical formulations [7]. CAP is $\mathrm{pH}$ sensitive polymer that is stable at acidic $\mathrm{pH}$ and depolymerizes at $\mathrm{pH}$ higher than 6.2. Consequently, $\mathrm{CAP}$ is stable in the acidic vaginal environment [8]. CAP was found to interfere with the virility of HIV-1, HSV-1 and HSV-2 indicating its potential use as a topical microbicide [9]. CAP acts as a HIV-1 entry inhibitor (for R4 and R5 tropic viruses) by binding to gp 120 and inducing a conformational change in the trimeric gp120/gp41 complex leading to six-helix bundles that render HIV-1 unable to fuse with the host cell membrane [10,11]. CAP can also induce disintegration of HIV-1 by stripping envelope glycoproteins to cause reduced viral infectivity [10-12]. CAP was found to be active against HIV-1 in soluble and insoluble form suggesting that CAP can prevent HIV-1 infection in vaginal lumen (cervicovaginal mucus) as well as vaginal mucosa [12]. Vaginal application of a gel containing micronized CAP $(13 \% w / v)$ did not alter vaginal $\mathrm{pH}$, vaginal microflora, or integrity of vaginal epithelium and prevented SHIV infection in macaques [13-15]. However, in a phase 1 clinical trial, CAP infused gel was found to cause unacceptable vulvo-vaginal side effects due to very high osmolarity of gel [16]. Further in vitro studies showed that exposure to $0.05 \mathrm{mg} / \mathrm{mL}$ of CAP fibers resulted in neutralization of HIV-1. These CAP fibers were minimally toxic to vaginal epithelial cells at concentrations of up to $1.8 \mathrm{mg} / \mathrm{mL}$ [16].

Recently, antiretroviral drugs (ARVs) such as the reverse transcriptase inhibitors etravirine (ETR) and tenofovir disproxil fumarate (TDF) have been encapsulated into CAP electrospun fibers [17]. Complete neutralization of viral particles in a non-cellular environment was reported upon incorporation of $17.8 \%$ (wt TDF/wt CAP polymer) of TDF. However, a major challenge faced was the ability of and the time required to deliver drug to cells by CAP electrospun fibers [18]. Consequently, there is a need for an alternative formulation approach for combined PrEP delivered by CAP and ARVs.

We have already shown that CAP nanoparticles (NPs) can enhance anti-HIV efficacy when delivered in combination with antiretroviral drugs such as efavirenz [19]. Our synthesis of CAP nanoparticles delivering antiretroviral drug in an osmotically neutral thermosensitive (TMS) gel demonstrated in principle that nanocellulose-based fabrications can: (1) offer sustained release of drug; (2) improve cellular permeability and uptake; (3) improve chemical, enzymatic and metabolic stability of drug; and (4) improve local/systemic biodistribution of the drug $[7,20]$. We expand these preliminary studies to demonstrate here that nanoformulation of the $\mathrm{pH}$ sensitive, topical microbicide CAP in combination with antiretroviral drugs (ARVs) may prevent entry as well as integration of HIV-1 within the human genome, and may be a viable and potent option for HIV-1 prophylaxis [4,21].

Integrase is a key enzyme for integration of HIV-1 into host cell genome [22]. Since integrase has no human homolog, HIV-1 integrase strand transfer inhibitors (ISTIs) have become a primary treatment option. Dolutegravir (DTG) has been approved by the FDA for HIV-1 treatment [22]. DTG is a second-generation integrase inhibitor that has potent activity against wild-type HIV-1 (EC 50 : 0.51-1.6 nM and protein-adjusted $\mathrm{EC}_{90}: 64 \mathrm{ng} / \mathrm{mL}$ ) and can inhibit various strains of HIV-1 at nanomolar concentrations [23-28]. DTG solution is more effective than other ISTIs at inhibiting 
HIV-1 infection of peripheral blood monocytes (PBMCs) [23]. DTG presents a higher barrier against the development of resistance as compared to other ISTIs. DTG has a diminished rate of dissociation from the integrase enzyme in wild type HIV and HIV strains with the N155, Q148 or Y143 mutations [24-28]. Consequently, DTG retains activity against ISTI resistant HIV strains [24-29] and clinical trials have shown that DTG is capable of reducing viral load in patients harboring ISTI resistant HIV-1 strains [30,31]. DTG is also effective against nucleoside reverse transcriptase inhibitor (NRTI), non-nucleoside reverse transcriptase inhibitor (NNRTI) and protease inhibitor (PI)-resistant isolates [23]. All these features indicate that DTG could be a novel candidate for topical HIV PrEP delivery by CAP nanoparticles.

This is the first report of the synthesis and cellular tolerability of cellulose-based integrase strand transfer inhibitor nanofabrications designed for female PrEP. Additional studies on anti-HIV efficacy of these nanofabrications are underway.

\section{Materials and Methods}

\subsection{Materials}

From Sigma-Aldrich (St. Louis, MO, USA), CAP ( $M_{\mathrm{W}}$ : 2534.12), Poly(vinyl alcohol) (PVA) ( $M_{\mathrm{W}}$ : 13,000-23,000), Acetone, Acetonitrile (ACN), Potassium dihydrogen phosphate (KH2PO4), and Phosphate Buffered Saline (PBS) were purchased. Dimethyl Sulfoxide (DMSO) was purchased from Fisher BioReagents and Fisher Chemicals (Fair Lawn, NJ, USA). Fetal Bovine Serum (FBS), Trypsin and Penicillin-Streptomycin (Pen/strep) solution was purchased from Hyclone ${ }^{\mathrm{TM}}$ (Logan, UT, USA). Gibco ${ }^{\mathrm{TM}}$ Dulbecco's Modified Eagle Medium (DMEM), Dolutegravir (DTG; 99\% purity), Pluronic F127 (PF-127), and Rhodamine 6G dye (Rho6G; 99\% purity) were purchased from FisherThermo Scientific (Rochester, NY, USA), Sequoia Research Products Ltd. (Pangbourne, UK), D-BASF (Edinburgh, UK), and Acros Organics (Geel, Belgium), respectively. Dolutegravir (DTG; $99 \%$ purity) was also obtained as a generous gift from ViiV Healthcare (Middlesex, UK). 3,3'-Dioctadecyl-5,5'-Di(4-Sulfophenyl)Oxacarbocyanine (DiO) dye, and DAPI dye were purchased from Life Technologies (Eugene, OR, USA). Paraformaldehyde (PFA) was purchased from Fisher BioReagents and Fisher Chemicals (Fair Lawn, NJ, USA). Keratinocyte-Serum Free medium (GIBCO-BRL 17005-042), human recombinant EGF, bovine pituitary extract, and calcium chloride were purchased from FisherThermo Scientific (Rochester, NY, USA). When appropriate, ultrapure water was used for all the experiments. All reagents were used as received without further purification.

\subsection{Nanoparticles Preparation and Characterization}

Drug or dye loaded CAP-NPs were prepared by interfacial polymer deposition method by water-in-oil-in-water (W-O-W) or oil-in-water $(\mathrm{O}-\mathrm{W})$ emulsion technique with some modifications [32-35]. Briefly, $50 \mathrm{mg}$ of CAP was dissolved in the $5 \mathrm{~mL}$ Acetone (the organic phase) containing $50 \mathrm{mg}$ of PF-127 as stabilizer. To formulate DTG loaded CAP-NPs (DTG-CAP-NPs), DTG $(5 \mathrm{mg})$ in $2.5 \mathrm{~mL}$ of $0.5 \%$ PVA was added drop-wise on the above mentioned organic phase under constant magnetic stirring, followed by 5 min sonication having $10 \mathrm{~s}$ bursts $(90 \%$ amplitude and 0.9 cycle), resulting in water-in-oil (W-O) emulsion. Further, the above $\mathrm{W}-\mathrm{O}$ emulsion was subsequently added drop wise on to $10 \mathrm{~mL} 1 \%$ PVA solution under constant magnetic stirring, followed by 5 min sonication (at above mentioned setting) resulting in water-in-oil-in-water (W-O-W) emulsion. A similar method was followed to generate blank CAP-NPs (CAP-NPs) without using DTG. To formulate Rho6G loaded CAP-NPs (Rho6G-CAP-NPs), Rho6G (5 mg) was added to the above organic phase. The above organic phase was added drop-wise on to $10 \mathrm{~mL}$ of $1 \%$ PVA solution resulting in an oil-in-water $(\mathrm{O}-\mathrm{W})$ emulsion. The $\mathrm{O}-\mathrm{W}$ emulsion was then sonicated (at above mentioned setting) for $5 \mathrm{~min}$. For both formulations, the organic phase was eliminated by evaporation. Finally, the surfactants, free DTG or Rho6G, were washed off from NPs three times by dialysis using a dialysis-cassette (MWCO 20 kDa; Thermo Scientific; Rockford, IL, USA) with 2 L miliQ grade 
water (water with $18.2 \mathrm{~m} \Omega$ resistance). NPs were then freeze-dried in the Millrock LD85 lyophilizer (Kingston, NY, USA).

For physico-morphological characterization, an appropriate amount of freeze-dried NPs were evaluated. For dynamic light scattering analysis (DLS), $5 \mathrm{mg} / \mathrm{mL}$ of respective NPs were dissociated in ultrapure water (with $18.2 \mathrm{M} \Omega$ resistivity at $25^{\circ} \mathrm{C}$ ). The NPs were then sonicated for $10 \mathrm{~min}$. For size-distribution analysis, NPs were further diluted to $1 \mathrm{mg} / \mathrm{mL}$ and for surface charge distribution analysis NPs were further diluted to $2 \mathrm{mg} / \mathrm{mL}$. The size, polydispersity index (PDI) and zeta potential of the NPs was characterized by using the ZetaPlus Zeta Potential Analyzer (Brookhaven Instruments Corporation, Holtsville, NY, USA). Five batches of NPs were analyzed to verify the reproducibility of the formulation method.

The percentage encapsulation efficiency (EE\%) was evaluated by high performance liquid chromatography (HPLC) analysis (Shimadzu, Kyoto, Japan). However, for Rho6G EE\% evaluation, UV-Visible absorbance analysis was performed by Nanodrop 2000c/2000 UV-Vis Spectrophotometers (Thermo scientific, Rockford, IL, USA) [32]. Briefly, $1 \mathrm{mg}$ of DTG-CAP-NPs and Rho6G-CAP-NPs were disintegrated in $100 \mu \mathrm{L} 40 \% \mathrm{DMSO}$ and were spun (at $14,000 \times g$ for 5 min at $4{ }^{\circ} \mathrm{C}$ ) filtered through Amicon ${ }^{\circledR}$ Ultra Centrifugal filters (MWCO 30KDa; Merck KGaA, Darmstadt, Germany). DTG solution was used for the standard curve and a similar protocol was followed. Standards concentration ranges from 500 to $1.9 \mu \mathrm{g} / \mathrm{mL}$ were used to determine the standard curve $\left(r^{2}=0.99\right)$. HPLC analysis was carried out on Phenomenex C18 column $(150 \mathrm{~mm} \times 4.6 \mathrm{~mm}, 5 \mu \mathrm{m})$, using isocratic mobile phase ( $25 \mathrm{mM} \mathrm{KH} \mathrm{PO}_{4} 45 \%$ : ACN $55 \%$ ) at a flow rate of $0.5 \mathrm{~mL} / \mathrm{min}$. UV absorbance was measured at $260 \mathrm{~nm}$ for both DTG and Rho6G. Retention times of DTG and Rho6G were $6.3 \mathrm{~min}$ and $8.4 \mathrm{~min}$, respectively. The $\mathrm{EE} \%$ by the following formula:

$$
\mathrm{EE} \%=\frac{(\text { Amount of drug entrapped in NPs })}{(\text { Amount of drug added to the emulsion })} \times 100
$$

To evaluate the morphology of the NPs, Scanning Electronic Microscope (SEM) imaging was performed as described previously [32,36,37]. Briefly, after filtering NPs suspension through a Whatman ${ }^{\circledR}$ Nuclepore Track-Etch Membrane ( $\sim 50 \mathrm{~nm}$ pore size), the air-dried NP-bearing membrane was mounted on the SEM stub and sputter coated with a thin layer ( 3-5 nm thick) of chromium. The NPs on the membrane were imaged under a Hitachi S-4700 Field-emission SEM (New York, NY, USA).

\subsection{Drug Release Study}

To evaluate in vitro drug release efficiency, $5 \mathrm{mg}$ of DTG-CAP-NPs were dissolved in $1 \mathrm{~mL}$ of $50 \mathrm{mM}$ citrate buffer ( $\mathrm{pH} 4.2$ ) or in $10 \mathrm{mM}$ PBS (pH 7.4), respectively. A $200 \mu \mathrm{L}$ DTG-CAP-NP solution was collected at each respective time period ( $1 \mathrm{~h}, 1,4$ and 7 day). The solution obtained was spun (at $14,000 \times g$ for 5 min at $4{ }^{\circ} \mathrm{C}$ ) to remove NPs and filtered through Amicon ${ }^{\circledR}$ Ultra centrifugal filters (MWCO 30KDa; Merck KGaA, Darmstadt, Germany) for drug analysis. The DTG concentration was further evaluated by HPLC as described above. During data analyses, the volume correction factor was considered. The experiment was performed in triplicate for three independent experimental data sets. The released DTG concentration was evaluated by following equation:

$$
\% \text { DTG release at time }{ }^{\prime} t_{n}^{\prime}=\frac{\text { Drug amount obtained at time }{ }^{\prime} t^{\prime}}{\text { Total amount in NP at respective volume }} \times 100
$$

$$
\% \text { actual DTG release at }{ }^{\prime} t^{\prime}=\left(\% \text { DTG release at time }{ }^{\prime} t_{n}^{\prime}\right)-\left(\% \text { DTG released at time }{ }^{\prime} t_{n-1}^{\prime}\right)
$$

where " $t$ " is the time interval ( $1 \mathrm{~h}, 1,4$ and 7 day) and " $t_{n}$ " represents corresponding time sequence number (i.e., $1 \mathrm{~h}, t_{n}=1 ; 1$ day, $t_{n}=2$; etc.). 


\subsection{In Vitro Uptake of CAP-Rhod6G/DTG-NPs Viewed by Confocal Imaging}

VK2/E6E7 cells were dissociated from culture flasks and plated at $10^{4}$ cells per well on sterile four-chamber slides in supplemented VK2/E6E7 media. Slides were incubated overnight $(\mathrm{O} / \mathrm{N})$ at $37^{\circ} \mathrm{C}$ and $5 \% \mathrm{CO}_{2}$ to allow for adherence to the slide surface. CAP-Rhod6G-NP and Rhod6G solutions were diluted in $1 \mathrm{~mL}$ of sterile DI water to make a stock solution with a working concentration of $5 \mathrm{mg} / \mathrm{mL}$. NPs were applied to cells at a final concentration of $1 \mu \mathrm{g} / \mathrm{mL}$ final concentration of DTG or Rhod6G in supplemented VK2/E6E7 media. After cells had been exposed to NPs, cells were fixed at $30 \mathrm{~min}$ and 7 days in $4 \%$ paraformaldehyde in PBS solution then washed in triplicate with $1 \times$ PBS three times. To stain the plasma membrane, DiO membrane stain (\#V22886, Waltham, MA, USA) was applied at a dilution of 1:200 in Keratinocyte-Serum Free medium and incubation for 8 min at $37^{\circ} \mathrm{C}$. Plates were washed with $1 \times$ PBS three times. To stain the nucleus, cells were further incubated with DAPI ( $300 \mathrm{ng} / \mathrm{mL}$ ) for $15 \mathrm{~min}$, then washed twice with $1 \times$ PBS and mounted in Permafluor ${ }^{\mathrm{TM}}$ mounting media (\#TA-006-FM, Thermofisher Scientific, Waltham, MA, USA). Cover-slipped slides were then sealed using nail polish and dried on a slide warmer. These slides were imaged in Creighton University's Integrated Biomedical Imaging Facility on its IBIF Leica TCS SP8 MP Confocal Microscope at high magnification using a HC PL Apochromat $63 \times 1.4$ N.A. oil objective. To visualize the DAPI nuclear stain, $\mathrm{DiO}$ membrane stain, and the Rho6G CAP NPs, the excitation/emission spectra selected was 405/461 nm, 488/520 nm, and 530/552 nm, respectively. Confocal images were analyzed and orthogonal planar pictures were acquired from Leica LAS X Microscope Software (Wetzlar, Germany).

\subsection{Preparation of NP Dispersed in Thermosensitive (TMS) Gel}

The TMS gel was prepared by following the method we described previously, with a few modifications [34]. Briefly, to prepare TMS gel of $\mathrm{pH} 4.2$ and 7.4, a 30:0.7 ratio of Pluronic F127 to Pluronic F68 was dissolved in $50 \mathrm{mM}$ Citrate buffer (pH 4.2) and $10 \mathrm{mM}$ PBS (pH 7.4), respectively. The gelation was carried out at $4{ }^{\circ} \mathrm{C}$. To prepare NP dispersed TMS gel, a respective amount of NPs were dissolved in respective $\mathrm{pH}$ buffer and thoroughly dispersed, followed by addition of TMS gel ingredients as mentioned above. Further, the above-mentioned gelation procedure was followed. All procedures were performed under aseptic condition.

\subsection{TMS Gelation Property Analysis at Physiological Condition}

To evaluate the viscoelastic properties of TMS gel, the thermogelation point and dynamic viscosity were examined. Dynamic rheological analyses were performed using an AR2000 rheometer (TA Instruments, New Castle, DE, USA). TMS gel measurements were performed using stainless steel cone/plate geometry (diameter: $40 \mathrm{~mm}$; angle: $2^{\circ}$; gap: $50 \mu \mathrm{m}$ ). The torque ranged from $0.05 \mu \mathrm{Nm}$ to $200 \mu \mathrm{Nm}$. To evaluate the thermogelation point of the TMS gel, the measurement was subjected to temperature ramping from 10 to $45^{\circ} \mathrm{C}$, under constant strain $(0.1 \%)$ and oscillatory frequency $(1 \mathrm{~Hz})$. The results were evaluated as a function of temperature. The variation in elastic modulus $G^{\prime}$ and viscous modulus $G^{\prime \prime}$ were obtained from the phase angle from the Rheology Advantage data analysis software (provided along with the instrument).

To evaluate the real-time gelation property of the TMS gel at respective $\mathrm{pH} 4.2$ or 7.4, the above rheological studies were performed in presence of stimulated vaginal fluid (VF) or seminal fluid (SF). To estimate reproducibility, all experiments were replicated at least three times independently. The stimulated VF or SF were prepared following previously published methods without modification [33]. Briefly, the $200 \mu \mathrm{L}$ TMS gel at respective $\mathrm{pH} 4.2$ or 7.4 was added to $200 \mu \mathrm{L}$ VF or SF or VF plus SF, and were mixed well before dispensing on the rheometer slab at $10{ }^{\circ} \mathrm{C}$ (Section 3.2).

\subsection{Vaginal Epithelial Cell Culture}

Human vaginal epithelial cell lines (VK2/E6E7 ATCC ${ }^{\circledR}$ CRL2616 ${ }^{\mathrm{TM}}$ ) were obtained from American Type Culture Collection (Manassas, VA, USA) and cultured according to their instructions. 
Briefly, VK2/E6E7 cells were cultured to $75 \%$ confluency in Keratinocyte-Serum Free medium (GIBCO-BRL 17005-042) with $0.1 \mathrm{ng} / \mathrm{mL}$ human recombinant EGF, $0.05 \mathrm{mg} / \mathrm{mL}$ bovine pituitary extract, and additional calcium chloride $44.1 \mathrm{mg} / \mathrm{L}$ (final concentration $0.4 \mathrm{mM}$ ) (supplemented VK2/E6E7 media) at $37^{\circ} \mathrm{C}$ and $5 \% \mathrm{CO}_{2}$. Cells were sub-cultured every 3 days using $0.25 \%(w / v)$ Trypsin-0.03\% (w/v) EDTA solution (\#SV30031.01, Waltham, MA, USA).

\subsection{Cytotoxicity Assay}

To evaluate the DTG-CAP-NPs and DTG-CAP-NPs-Gel cytotoxicity to vaginal epithelial cells, the vaginal epithelial cell line, VK2/E6E7 cells, were used. For in vitro cytotoxicity experiments using VK2/E6E7 cells, cells $\left(2 \times 10^{4}\right.$ cells/well) were placed into 96-well plates overnight in their respective media (described above). For each type of NPs and pH, where TMS gel is at $\mathrm{pH} 4.2 \mathrm{or} \mathrm{pH}$ 7.4, separate experiments were run. For each set, the following variables were tested: blank CAP-NPs, blank CAP-NPs in respective TMS gel pH 4.2 or 7.4, DTG solution, DTG solution in respective TMS gel pH 4.2 or 7.4, DTG-CAP-NPs, DTG-CAP-NPs in respective TMS gel pH 4.2 or 7.4, untreated (the negative cytotoxicity control sample) and $5 \%$ triton- $X$ (the positive cytotoxicity control sample). Each treatment variable was added to the cells in triplicate wells and incubated at $37{ }^{\circ} \mathrm{C}, 5 \% \mathrm{CO}_{2}$ over the course of 24, 48, or $96 \mathrm{~h}$. The DTG concentrations in solution and entrapped in NPs was 10, 1, 0.1, $0.01,0.001,0.0001 \mu \mathrm{g} / \mathrm{mL}$. At pre-specified intervals $(24,48$, and $96 \mathrm{~h})$, the cell viability was estimated by using the Cell Titer-Glo kit (Promega; Madison, WI, USA) following manufacturer's protocol. Cell viability results were measured using a baseline subtraction method from the luminometer. The data presented were normalized to the untreated control (100\% viability). The results were assessed using analysis of variance (ANOVA). Graphs present results from three independent experiments as means \pm standard deviation (SD) or standard error (SE) as indicated.

\subsection{Statistical Analysis}

All experiments were performed in triplicate unless noted otherwise. Data analyses of nanoparticle physiochemical characteristics are presented as the mean \pm standard deviation (SD). All other experiments are presented as the mean \pm standard error (SE). Cellular data were analyzed by two-way analysis of variance (ANOVA) followed by post hoc (Tukey's multiple comparison test) and Pearson's correlation using GraphPad Prism 5 software (La Jolla, CA, USA). Significant differences were considered significant at $p<0.05\left(^{*}\right)$.

\section{Results}

\subsection{Cellulose Acetate Phthalate Nanoparticle (CAP-NP) Characterization}

To examine the potential of CAP-NPs for sustained delivery of DTG, DTG-CAP-NPs were first fabricated and characterized for in vitro incorporation into TMS gel and for cellular viability assays. Rho6G-CAP-NPs were fabricated and characterized for cellular localization studies. The physiochemical characteristics of DTG or Rhod6G uploaded CAP-NPs at a neutral $\mathrm{pH}$ are summarized in Table 1. DTG-CAP-NPs and Rhod6G-CAP-NPs obtained by the modified O/W emulsion had a mean particle size of $\sim 200 \mathrm{~nm}$ diameter and were monodispersed as indicated by a polydispersity index (PDI) $<0.2$. Surface charge analysis showed that NPs were weakly negatively charged $(<-30 \mathrm{mV})$. The encapsulation efficiency (EE\%) of CAP-NPs for DTG loading was over 70\%. The encapsulation efficiency (EE\%) of CAP-NPs for Rhod6G loading was over $50 \%$.

To determine the topography of DTG-CAP-NPs, scanning electron microscopy imaging was performed. Figure 1A shows an electron microscope image of DTG-CAP-NPs illustrating the uniform and smooth spherical surface. Since the vaginal environment is acidic ranging from $\mathrm{pH} 3.5$ to $\mathrm{pH} 4.7$ in $>65 \%$ of post-puberty, pre-menopausal women and since $\mathrm{CAP}$ is responsive to $\mathrm{pH}$, we compared the size and polydispersity of DTG-CAP-NPs in an average vaginal environment ( $\mathrm{pH} 4.2)$ to a neutral $\mathrm{pH}$ that would be similar to seminal fluid ( $\mathrm{pH}$ 7.4). To expand our preliminary data analyses 
evaluating NP size immediately upon sample preparation, we compared the size and polydispersity of DTG-CAP-NPs at pH 4.2 and pH 7.4 over a one-week (168 h) period (Figure 1B). Detailed analysis of the size of three additional batches of DTG-CAP-NPs demonstrates some variability and shows that overall the NPs are less than $200 \mathrm{~nm}$ in diameter and will function as nanoparticles. After one hour in a vagina-like pH 4.2 environment, DTG-CAP-NPs were $125 \pm 19 \mathrm{~nm}$. After one hour in a seminal-fluid-like environment of $\mathrm{pH}$ 7.4, DTG-CAP-NPs were $131 \pm 8 \mathrm{~nm}$. Over the course of one week the diameter of DTG-CAP-NPs at $\mathrm{pH} 4.2$, did not significantly change. DTG-CAP-NPs were $125 \pm 15 \mathrm{~nm}$ in size at $168 \mathrm{~h}(\sim 0 \%$ change). Contrastingly, the diameter of DTG-CAP-NPs at $\mathrm{pH} 7.4$ decreased $\sim 35.9 \%$ from $131 \pm 8 \mathrm{~nm}$ to $99 \pm 15 \mathrm{~nm}$ within $24 \mathrm{~h}$. After $24 \mathrm{~h}$ and up to $168 \mathrm{~h}$, DTG-CAP-NPs decreased in size to $84 \pm 17 \mathrm{~nm}$. The polydispersity index (PDI) of DTG-CAP-NPs was also compared over the course of one week (Figure 1B) to estimate aggregation and disintegration properties of NPs at $\mathrm{pH} 4.2$ or $\mathrm{pH} 7.4$ over time. DTG-CAP-NPs in an average vagina-like $\mathrm{pH}$ of 4.2 maintained their monodispersity, as demonstrated by an averaged PDI of $0.04 \pm 0.03$ at one hour that was consistent with a PDI of $0.03 \pm 0.02$ at $168 \mathrm{~h}$. The very low PDI values of DTG-CAP-NPs at $\mathrm{pH} 4.2$ are likely due to the $\mathrm{pH}$ sensitivity of CAP. However, in the seminal fluid-like $\mathrm{pH}$ of 7.4, DTG-CAP-NPs exhibited an average PDI of $0.169 \pm 0.06$ at one hour that increased significantly to $0.367 \pm 0.04$ by $168 \mathrm{~h}$ (Figure $1 \mathrm{~B}, p<0.05$ ). These data suggest that DTG-CAP-NPs maintain their integrity at an acidic $\mathrm{pH}$ of 4.2 and that CAP depolymerizes at physiological $\mathrm{pH} 7.4$ reducing the size and increasing the diversity of NPs due to the formation of aggregates of disintegrated CAP polymer [38].

Table 1. Physiochemical Characterization of CAP Nanoparticles.

\begin{tabular}{ccccc}
\hline CAP-NP Sample & Size $(\mathbf{n m})$ & Surface Charge $(\mathbf{m V})$ & Polydispersity Index (PDI) & EE\% \\
\hline DTG-CAP-NP & $212.62 \pm 20.8$ & $-25.046 \pm 3.4$ & $0.189 \pm 0.025$ & $71.72 \pm 7.5$ \\
\hline Rhod6G-CAP-NP & $164.5 \pm 40.6$ & $-27.15 \pm 0.39$ & $0.166 \pm 0.0049$ & $53.9 \pm 6.33$ \\
\hline \multicolumn{5}{c}{ Data presented as mean \pm standard error of mean of six different NP batches $(n=6)}$.
\end{tabular}

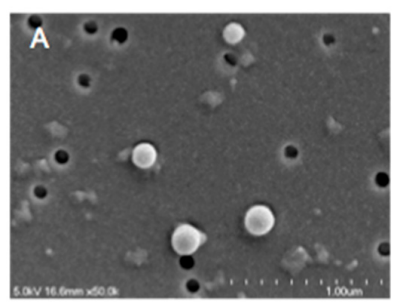

(A)

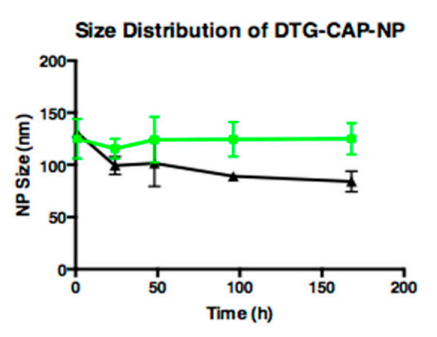

(B)

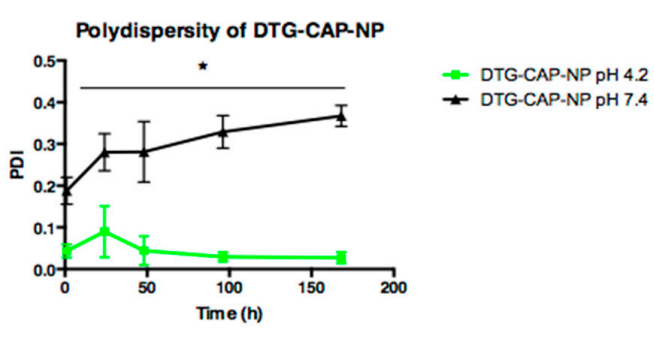

(C)

Figure 1. Characterization of DTG-CAP-NP. SEM of DTG-CAP-NP at pH 7.4. Scale bar shows $1.0 \mu \mathrm{m}$ (A); Size distribution of CAP-DTG-NP for $168 \mathrm{~h}$ at $\mathrm{pH} 4.2$ and $\mathrm{pH} 7.4$ (B); Polydispersity index of CAP-DTG-NPs for $168 \mathrm{~h}$ at $\mathrm{pH} 4.2$ and $\mathrm{pH} 7.4$ (C); Error bars represent SD. ${ }^{*} p<0.05$. 
To evaluate the DTG release profile from DTG-CAP-NPs, the amount of DTG drug released over a one-week period from DTG-CAP-NPs at $\mathrm{pH} 4.2$ and $\mathrm{pH} 7.4$ was analyzed by HPLC (Figure 2). As expected, in physiological buffer (pH 7.4), DTG-CAP-NPs released $81.2 \% \pm 0.02 \%$ of the entrapped DTG within one hour of incubation and, by the end of Day 7 , only $3.2 \% \pm 0.27 \%$ remained entrapped in the DTG-CAP-NPs. This finding supports our assumption that DTG-CAP-NPs disintegrate and rapidly deliver DTG at physiological $\mathrm{pH}$ similar to $\mathrm{pH}$ 7.4. Following one-hour incubation in $\mathrm{pH} 4.2$ buffer, only $39.8 \% \pm 0.10 \%$ DTG was released from DTG-CAP-NPs. Moreover, after one week at $\mathrm{pH} 4.2,39.2 \% \pm 1.33 \%$ of DTG was retained in DTG-CAP-NPs. The previously documented $\mathrm{pH}$ sensitivity of CAP [36] and our data showing a 36\% decrease in size, increased PDI, and release of $\sim 80 \%$ of DTG from DTG-CAP-NPs in one hour at $\mathrm{pH} 7.4$, suggest that CAP disintegrated at $\mathrm{pH} 7.4$. As a result, it is likely that DTG-CAP-NPs will release their content instantaneously when vaginal fluid of varying acidic $\mathrm{pH}$ intermixes with seminal fluid.

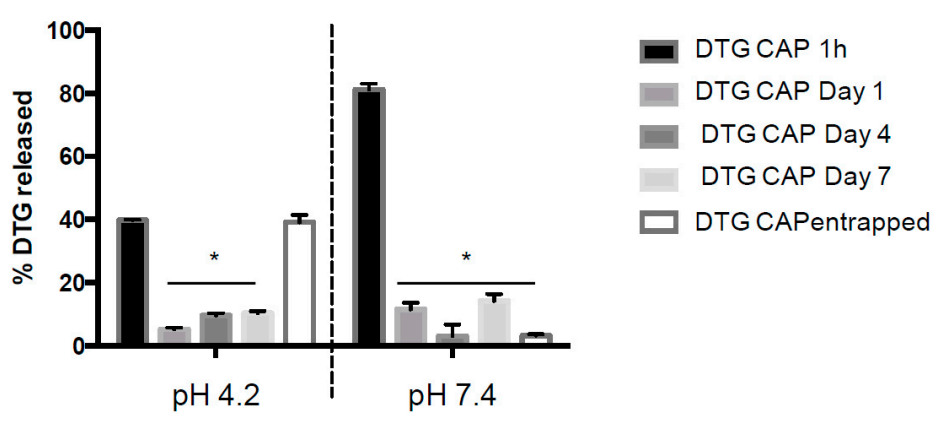

Figure 2. Percent of Entrapped DTG Released from DTG-CAP-NP. In vitro and HPLC analysis of DTG release from DTG-CAP-NPs over a one-week time at $\mathrm{pH} 4.2$ and $\mathrm{pH}$ 7.4. DTG-CAP entrapped represents the amount of DTG remaining entrapped in the NP at the end of the one-week experiment. Error bars represent standard error of mean (SEM). ${ }^{*} p<0.05$.

To investigate whether nano-encapsulation of DTG in CAP-NPs ensure cellular uptake and retention, we conducted cellular uptake studies and evaluated uptake efficiency by confocal imaging. To visualize under confocal fluorescent microscope, we used Rhod6G loaded NPs (Rho6G-CAP-NPs) and compared NP uptake with Rhod6G solution (Rhod6G Sol) at respective time points over one week. In Figure 3, Rho6G solution (free Rho6G dye) and Rhod6G-CAP-NPs are visualized as red fluorescence, the nuclei are stained with DAPI and are visualized as blue fluorescence and cellular membranes stained with $\mathrm{DiO}$ are visualized as green fluorescence. Both Rho6G solution and Rhod6G-CAP-NP treated cells show Rho6G fluorescence within 30 min of treatment. In both Rhod6G Sol and CAP-Rhod6G-NP treatments, co-localization (orange) of the Rho6 G red fluorescence and the membrane green fluorescence suggests that the dye and/or NPs are proximal to or potentially incorporated into cellular membranes. Orthogonal view of the cell for both Rhod6G Sol and Rhod6G-CAP-NP suggest that delivery of solution and NP was intracellular (Figure 3). However, at Day 7 incubation Rho6G fluorescence was observed in Rhod6G-CAP-NPs treated VK2/E6E7 cells while in Rhod6G solution treated cells Rho6G fluorescence was not present. The orthogonal view of treated cells demonstrated that Rhod6G-CAP-NP show intracellular fluorescence near the nucleus at the seven-day time point (Figure 3). To further evaluate the above finding in cellular population, we next determined the percent of cells treated with these NPs that showed presence of Rho6G at $30 \mathrm{~min}$ and Day 7 of treatment (Figure 4). The number of Rhod6G-CAP-NPs positive cells as determined by red fluorescence at $30 \mathrm{~min}$ and seven day time points were divided by the total number of cells counted per field. Results show Rhod6G-CAP-NPs entered $96 \% \pm 1.5 \%$ of cells at $30 \mathrm{~min}$ and were retained even after seven days at $98 \% \pm 1.0 \%$ (Figure 4 ). 

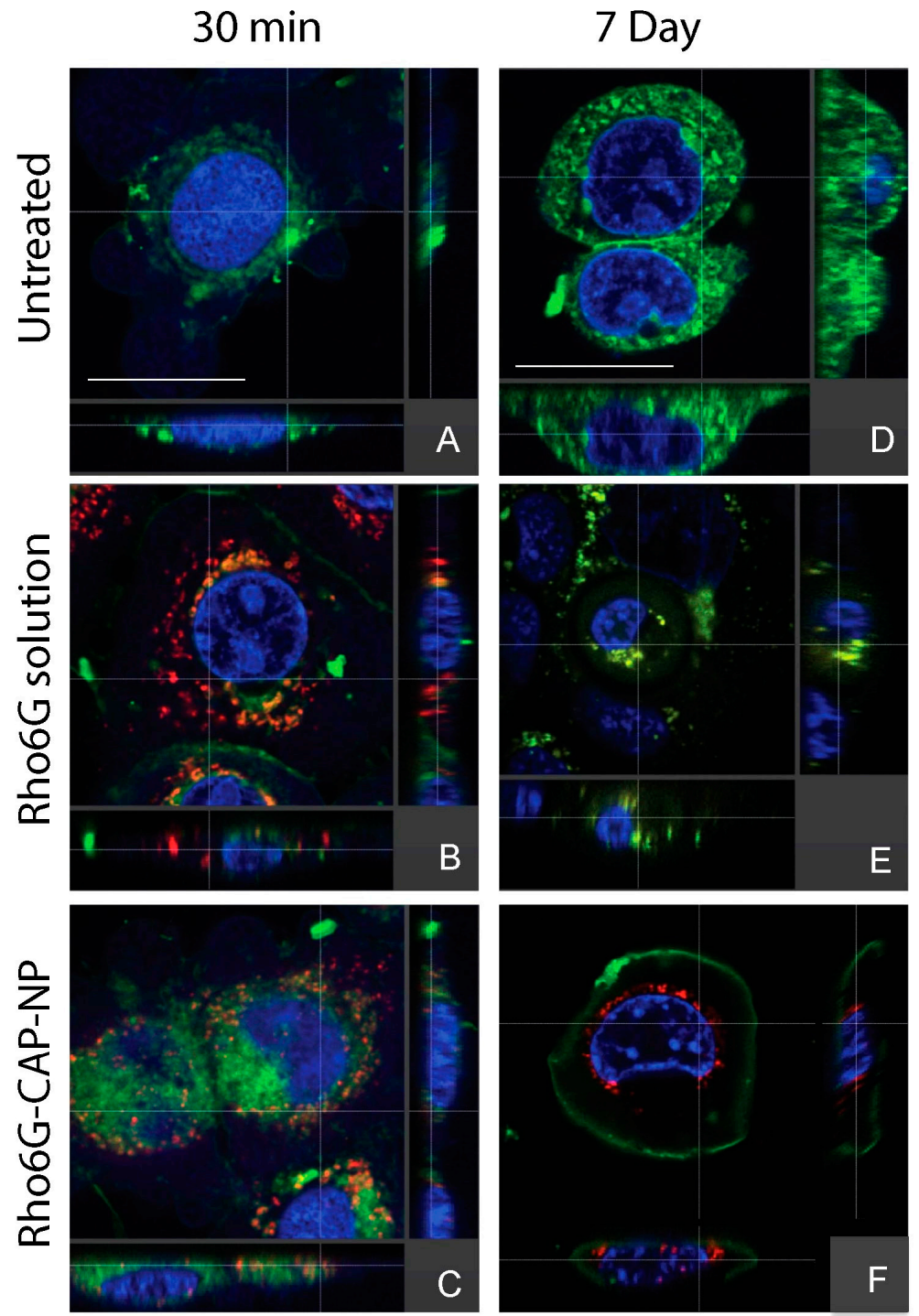

Figure 3. Translocation of Rhod6G Solution or Rhod6G-CAP-NPs to Vaginal Epithelial cells (VK2/E6E7). Rhod6G Solution (red) or Rhod6G-CAP-NPs at: $30 \mathrm{~min}(\mathbf{A}-\mathbf{C})$; and seven days (D-F) post-treatment. Orthogonal Plane Images were obtained and evaluated by the IBIF Leica TCS SP8 MP Confocal Microscope at $63 \times$ with $5 \times$ computational magnification. DAPI: blue, DiO: green, Rhodamine: red. (A)/(D): Untreated, (B)/(E): Rhodamine Solution $(1 \mu \mathrm{g} / \mathrm{mL}),(\mathbf{C}) /(\mathbf{F})$ : Rhod6G-CAP-NPs $(1 \mu \mathrm{g} / \mathrm{mL})$. Scale bar $=13 \mu \mathrm{m}$ and is applicable to $(\mathbf{B}-\mathbf{F})$. For visualization of nanoparticles in print, scale bars are omitted from (B-F), and contrast and brightness were enhanced using imaging software. 

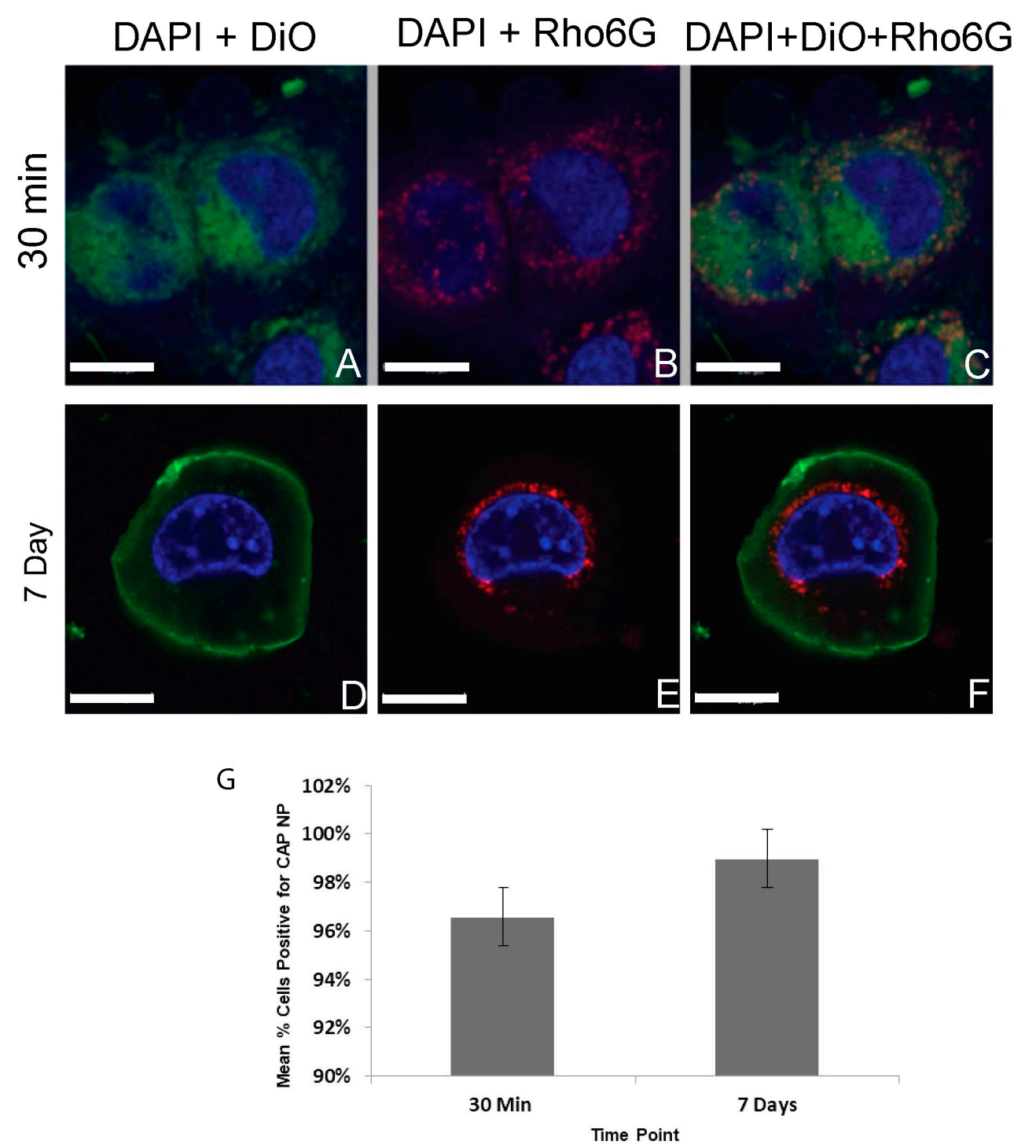

Figure 4. VK2/E6E7 vaginal epithelial cells treated with Rhod6G-CAP-NPs at $(1 \mu \mathrm{g} / \mathrm{mL})$ at: $30 \mathrm{~min}(\mathrm{~A}-\mathrm{C})$ and seven days (D-F) post-treatment. DAPI: Blue; DiO: Green; Rhodamine: Red. (A) DAPI + DiO; (B) DAPI + Rho; and (C) DAPI + DiO + Rho. (G) Mean percent VK2/E6E7 cells containing Rhod6G-CAP-NPs over time. 10× and 20× imaged on IBIF Leica TCS SP8 MP Confocal Microscope images analyzed in ImageJ $(n=4)$. For visualization of nanoparticles in print, contrast and brightness were enhanced using imaging software. $(G)$ The percentage cells with Rho6G-CAP-NPs over seven days. Error bars reflect standard error of the mean, and the mean percent of cells containing Rhod6G-CAP-NP at $30 \mathrm{~min}$ and seven days was not significantly different $(p>0.05)$.

\subsection{TMS Gelation Property Evaluation}

One of the topical pre-exposure prophylactics (PrEP) for HIV infection is drug application vaginally or rectally that protect at-risk individuals from HIV and other sexually transmitted infections. Our strategy to fabricate DTG-CAP-NPs incorporated into TMS gel for use as a vaginal microbicide combines microbicide and ISTI to potentially provide enhanced PrEP for females. In our previous study, we found that CAP-NPs can be successfully incorporated into TMS gel to deliver ARV into cervical cells [19]. In the present study, with some modification, TMS gel was formulated at vaginal pH 4.2 and seminal $\mathrm{pH}$ 7.4. To evaluate the gelation properties of TMS gel samples at resting condition without disrupting the microstructure formation during gelation process, the viscoelastic measurements of TMS 
polymer gels near the sol-gel transition state were determined by dynamic rheological studies [33]. The thermogelation study revealed that TMS gel at $\mathrm{pH} 7.4$ and $\mathrm{pH} 4.2$ thermogelates at around $21.8 \pm 1{ }^{\circ} \mathrm{C}$ and $15.2 \pm 1.4{ }^{\circ} \mathrm{C}$, respectively (Table 2). However, the presence of physiological fluids at the site of infection (i.e., VF and SF) does interfere with the thermogelation property of TMS gel. In the case of TMS gel at $\mathrm{pH} 4.2$, the presence of $\mathrm{VF}$ or SF or both shows low to no gelation at $37^{\circ} \mathrm{C}$ (Table 2). Moreover, even though the thermogelation temperature of TMS gel at pH 7.4 in presence of VF or SF or both is $<37^{\circ} \mathrm{C}$, a clear shift of $<10^{\circ} \mathrm{C}$ of thermogelation temperature was observed (Table 2).

Table 2. Thermogelation property evaluation of TMS gel.

\begin{tabular}{ccccc}
\hline Sample & Vaginal Fluid (VF) & Seminal Fluid (SF) & $\begin{array}{c}\text { TMS Gel:VF or } \\
\text { SF Ratio }\end{array}$ & $\begin{array}{c}\text { Thermogelation } \\
\text { Temp. }\left({ }^{\circ} \mathrm{C}\right)\end{array}$ \\
\hline TMS gel (pH 4.2) & - & - & - & $21.8 \pm 1$ \\
TMS gel (pH 4.2) in VF & + & - & $1: 1$ & $37.9 \pm 4.2$ \\
TMS gel (pH 4.2) in SF & - & + & $1: 1$ & $>40$ \\
TMS gel (pH 4.2) in VF + SF & + & - & $1: 1$ & $38.6 \pm 2.9$ \\
TMS gel (pH 7.4) & - & - & - & $15.2 \pm 1.4$ \\
TMS gel (pH 7.4) in VF & + & + & $1: 1$ & $36.4 \pm 0.23$ \\
TMS gel (pH 7.4) in SF & - & + & $1: 1$ & $35.7 \pm 2.6$ \\
TMS gel (pH 7.4) in VF + SF & + & + & $1: 1$ & $29.2 \pm 6.7$ \\
\hline
\end{tabular}

\subsection{Cytotoxicity of $C A P-D T G-N P$}

DTG-CAP-NPs are a novel formulation designed to improve PrEP for HIV. As DTG-CAP-NPs are aimed to be delivered at the site of infection, i.e., on the vaginal epithelial layer, a primary question is whether DTG-CAP-NP fabrication can be delivered to vaginal cells without causing cytotoxicity. Cytotoxicity studies at $\mathrm{pH} 7.4$ suggest that there is no significant difference in cellular viability when VK2/E6E7 are treated with CAP-NP, DTG-CAP-NP or DTG solution, when DTG drug concentrations are $<1000 \mathrm{ng} / \mathrm{mL}$. However, at concentrations $\geq 1000 \mathrm{ng} / \mathrm{mL}$, moderate cytotoxicity was observed in DTG-CAP-NP and DTG solution treatments. At highest treatment concentration, i.e., $10,000 \mathrm{ng} / \mathrm{mL}$, the viability at $24 \mathrm{~h}$ post-treatment was decreased by $23.01 \% \pm 4.3 \%$ and $25.6 \% \pm 4.3 \%$ for DTG-CAP-NP and DTG solution, respectively (Figure 5). Therefore, DTG-CAP-NPs were less cytotoxic to cells at $24 \mathrm{~h}$ than DTG solution by over $2.5 \%$ but this was not significant $(p>0.05)$. The $48 \mathrm{~h}$ post-treatment viability study illustrated that DTG-CAP-NP were less cytotoxic than DTG solution at $10,000 \mathrm{ng} / \mathrm{mL}$ and reduced viability by $36.52 \% \pm 6.568 \%$ instead of $44.85 \% \pm 6.568 \%$ as compared to control untreated cell viability. However, the improved viability of the DTG-CAP-NP treatment as compared to DTG solution of $\sim 8 \%$ was not significant $(p>0.05)$ and both conditions are significantly more cytotoxic than untreated control cells. At $96 \mathrm{~h}$, DTG-CAP-NP and DTG solution decreased cell viability when the DTG concentration was at $10,000 \mathrm{ng} / \mathrm{mL}$ by $\sim 42.7 \%$ and $~ 56.0 \%$ as compared to control. Again, DTG-CAP-NPs at the highest concentration tested are less cytotoxic than DTG solution by $\sim 13 \%$ but this difference was not significant using our analyses $(p>0.05)$. Treatment with $5 \%$ Triton-X induced cell death and is used as a negative control. Significant differences were determined using multiple comparison of two-way ANOVA followed by Tukey's post-test.

\subsection{Cytotoxicity of CAP-NPs in TMS Gel}

To determine the cytotoxicity of DTG-CAP-NPs in $\mathrm{pH} 4.2$ and $\mathrm{pH} 7.4$ in gel, in vitro cytotoxicity assays were performed (Figure 6). Interestingly gel delivery of CAP-DTG-NPs (CAP-DTG-NP-Gel) at $\mathrm{pH} 7.4$ is not cytotoxic to VK2/E6E7 cells even at the highest concentrations of DTG $(n=3, p>0.05)$. Cell viability of CAP-DTG-NP-Gel at $\mathrm{pH} 7.4$ was not significantly different from the viability of untreated control cells $(p>0.05)$. CAP-DTG-NP-Gel at pH 4.2 was cytotoxic to VK2/E6E7 cells and the acidic $\mathrm{pH}$ reduced viability similar to $5 \%$ Triton-X treatment. Both CAP-DTG-NP-Gel at pH 4.2 and $5 \%$ Triton- $X$ treatments were significantly cytotoxic as compared to CAP-DTG-NP-Gel at pH 7.4 
and untreated conditions ( $p<0.05$, Figure 6). Significant differences were determined using multiple comparison of two-way ANOVA followed by Tukey's post-test.
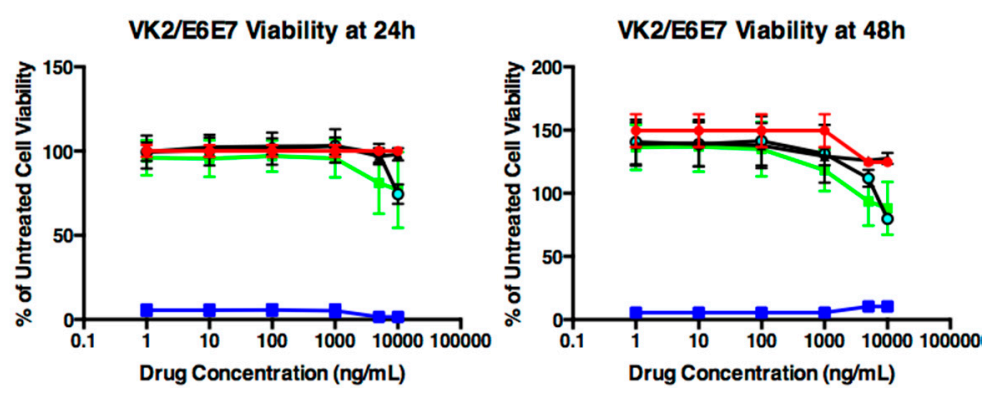

VK2/E6E7 Viability at $96 \mathrm{~h}$

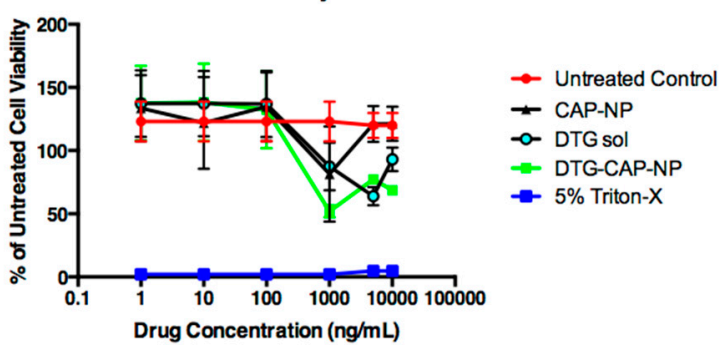

Figure 5. Vaginal epithelial VK2/E6E7 cell viability following treatment with DTG sol, CAP-NPs, and DTG-CAP-NPs at pH 7.4 $(n=6)$. Untreated control cells were used to indicate normal cell growth for three days in culture. Five-percent Triton-X treatment was used as a cytotoxicity control. Error bars represent SD.

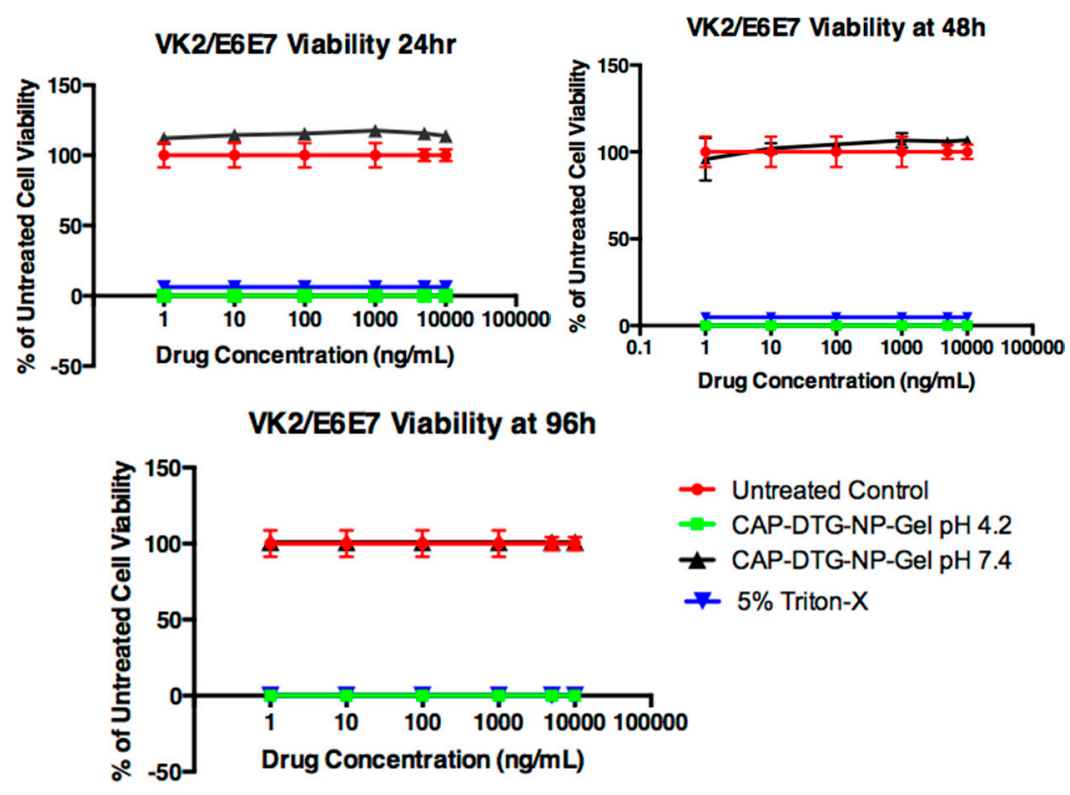

Figure 6. Vaginal epithelial VK2/E6E7 cell viability following treatment with DTG-CAP-NP-Gel at pH $7.4(n=6)$. Error bars represent SD.

\section{Discussion}

Topical microbicides that provide PrEP for females could reduce HIV-1 transmission dramatically [35]. CAP is FDA approved and widely used as a pharmaceutical excipient that displays microbicidal properties by inhibiting HIV in both its soluble and insoluble form by directly binding 
gp120 and interfering with p41Gag [9,11]. Additionally, the phthalate function group of CAP is $\mathrm{pH}$ sensitive ( $\mathrm{pKa}$ of $\sim 5.5$ ) and undergoes a solution-to-gel phase transition as $\mathrm{pH}$ reaches neutral [36]. The microbicidal function and $\mathrm{pH}$ responsiveness of CAP suggests that CAP can be modified to effectively delivery antiretroviral drug for improved female HIV pre-exposure prophylaxis (PrEP). $\mathrm{CAP}$, as well as several other topical microbicides that exhibited anti-HIV activity in preclinical trials, failed in clinical trials because the formulation caused irritation to female vaginal tissue and/or demonstrated a lack of efficacy [39-41]. Nanofabrication for delivery of CAP microbicide and drug may reduce the current limitations of topical microbicides and highly active antiretroviral therapy (HAART) that are challenged by tissue irritation, dosing complexities, and potential development of HIV resistance. We and others have developed CAP into nanofabrications for ARV delivery and improved PrEP $[17,19]$ CAP electrospun nanofibers were designed to dissolve and release ETR or TDF within seconds to minutes after exposure to semen at $\mathrm{pH}$ 7.4. CAP fibers were minimally toxic to vaginal epithelial cells and could inhibit HIV virus in solution [17]. While fibers may offer the advantage of leak-free delivery system, fibers are challenged by their capacity to rapidly and effectively deliver drug to cells. Nanoparticles (NP) offer sustained release of drug and improved stability, permeability, cellular uptake, and local/systemic biodistribution of drug $[7,20]$. NPs that are readily taken up into cells and sustain drug delivery, particularly sustained delivery of drugs working prior to viral integration, may offer significantly improved PrEP.

The HIV-1 integrase strand transfer inhibitor (ISTI), DTG is a second-generation integrase inhibitor that has potent activity against wild-type $\mathrm{HIV}\left(\mathrm{EC}_{50}: 0.51-1.6 \mathrm{nM}\right)$ and can inhibit various strains of HIV at nanomolar concentration [23-28]. DTG presents a high barrier against development of resistance as compared to other ISTIs, e.g., raltegravir (RAL) or elvitegravir (EVG). DTG retains activity against RAL and/or EVG resistant HIV strains [24-29] and clinical trials have shown that DTG is capable of reducing viral load in patients harboring RAL and/or EVG resistant HIV-1 strains [30,31]. DTG is also effective against nucleoside reverse transcriptase inhibitor (NRTI), non-nucleoside reverse transcriptase inhibitor (NNRTI) and protease inhibitor (PI)-resistant isolates [23]. We hypothesized that DTG is an excellent candidate for topical HIV PrEP delivered by CAP-NPs for improved female PrEP.

For the first time, we present the synthesis of CAP-NPs encapsulating the ISTI DTG. DTG-CAP-NPs were synthesized using $\mathrm{O} / \mathrm{W}$ method to form a monodispersed $(\mathrm{PDI}<0.2)$ population of NP averaging $\sim 200 \mathrm{~nm}$ diameter. DTG-CAP-NPs were weakly negatively charged $(<-30 \mathrm{mV})$. The encapsulation efficiency (EE\%) of CAP-NPs for DTG loading was over $70 \%$. The size, polydispersity index and EE\% should allow for effective delivery of the ISTI DTG to cells over time (Table 1). DTG-CAP-NPs have a uniformly, smooth surface and demonstrate expected $\mathrm{pH}$ sensitivity over time (Figure 1A,B). While the vaginal $\mathrm{pH}$ among women varies depending upon age and ethnicity, DTG-CAP-NP synthesis was optimized for the average vaginal $\mathrm{pH}$ of 4.2 (range approximately $\mathrm{pH} 3.8-4.5$ ) and $\mathrm{pH}$ of seminal fluid at $\mathrm{pH} 7.4$ as proof-of-concept in these in vitro studies. The average $\mathrm{pH}$ for the vaginal environment in the majority ( $65 \%$ ) of post-puberty, pre-menopausal women was estimated to be approximately $\mathrm{pH}$ 4.2. At vaginal $\mathrm{pH} 4.2$, the DTG-CAP-NPs do not show any significant change in their average size or PDI values. However, at physiological $\mathrm{pH}$ similar to that of seminal fluid (pH 7.4), DTG-CAP-NPs significantly decrease in size and polydispersity increases, demonstrating the depolymerization of the CAP polymer leading to release of DTG. The capacity to release DTG is evident from the DTG release studies (Figure 2). At pH 7.4, DTG-CAP-NPs released over 80\% of the entrapped DTG and only $\sim 3 \%$ remained entrapped in DTG-CAP-NP after one week. However, at pH 4.2, DTG-CAP-NPs released DTG $<40 \%$ in $1 \mathrm{~h}$ which could be attributed to increase in surface tension on NPs upon resuspension after freeze drying [42]. DTG-CAP-NPs shows retention of $40 \%$ of DTG even after one week. These data suggest that DTG from DTG-CAP-NP could be instantaneously released onto vaginal epithelial cells when the vaginal $\mathrm{pH}$ becomes neutralized by the seminal fluid. Delivery of DTG to cells is necessary for the ISTI to function against HIV. We demonstrated using confocal imaging that Rhod6G-CAP-NP were readily taken up into $>95 \%$ of vaginal epithelial cells at $30 \mathrm{~min}$ and throughout the seven-day experiment (Table 1, and Figures 3 and 4). Rhod6G-CAP-NPs were seen in 
the cytoplasm and near the nucleus of cells. While Rhod6G solution alone can be observed in cells at $30 \mathrm{~min}$, Rhod6G solution is not observed in cells over a seven-day experiment. These data suggest that CAP-NPs can offer sustained delivery of DTG to cells over time and future studies are underway to confirm the delivery of DTG intracellularly. Further, since a body of work suggests that mucosal epithelial cells may provide a reservoir for HIV, delivery of microbicide and ISTI to vaginal epithelial cells directly could increase PrEP function [35].

The aim of present study was to develop a local NP delivery system that can potentially prolong retention of DTG-CAP-NPs at the target site. To reach this aim, a novel TMS gel fabrication was optimized at both $\mathrm{pH} 4.2$ and 7.4, to maintain DTG-CAP-NP colloidal stability upon incorporation into TMS gel and to target specific drug release during the a putative time of infection. TMS gel composition was optimized to ascertain that TMS gel thermogelates at around $37^{\circ} \mathrm{C}$ (Table 2). TMS gel fabrication provides a mechanism for vaginal application and delivery of $\mathrm{pH}$ sensitive, DTG-CAP-NPs to vaginal cells. Thermogelation upon application of DTG-CAP-NPs in TMS gel (DTG-CAP-NP-Gel) should allow maintenance of NPs at the vaginal epithelium over time. In vivo imaging studies determining the sustained delivery of NPs in gel to cells are underway. Since vaginal epithelial cells would be in direct contact with DTG-CAP-NPs via gel delivery, we examined the cytotoxicity of DTG-CAP-NPs and DTG-CAP-NP-Gel to vaginal epithelial cells (Figure 6). DTG-CAP-NPs in solution and in gel were not cytotoxic to vaginal epithelial cells at concentrations of DTG $<1000 \mathrm{ng} / \mathrm{mL}$. Some cytotoxicity was seen when DTG-CAP-NPs were delivered in solution to vaginal epithelial cells and the DTG concentration is $>1000 \mathrm{ng} / \mathrm{mL}$ (Figure 6). Our viability assays demonstrate that DTG-CAP-NPs at the highest treatment concentration of $10,000 \mathrm{ng} / \mathrm{mL}$ trend toward being increasingly less cytotoxic than DTG solution. The CAP-NP fabrication method is likely to provide a mechanism for drug delivery that is more tolerated by cells over time. DTG-CAP-NP-Gel at $\mathrm{pH} 4.2$ were cytotoxic to vaginal epithelial cells since these modified cells are $\mathrm{pH}$ sensitive and must be cultured at physiological $\mathrm{pH}$. Cell death at $96 \mathrm{~h}$ in the TMS gel at $\mathrm{pH} 4.2$ is due to the response of these cells to acidic $\mathrm{pH}$ and the absence of the normal tissue environment. However, studies using vaginal tissue explants and animals are underway to determine the potential for tissue irritation following vaginal application of DTG-CAP-NP-Gel at pH 4.2. Importantly, no cytotoxicity was seen when DTG-CAP-NP-Gel were delivered to vaginal epithelial cells at $\mathrm{pH} 7.4$ as compared to untreated control conditions (Figure 6). Previous studies using monkey model systems showed that vaginal application of a gel containing micronized CAP $(13 \% w / v)$ did not alter vaginal $\mathrm{pH}$, vaginal microflora, or integrity of vaginal epithelium and prevented SHIV infection [13-15] strongly suggesting CAPs usefulness in female PrEP. However, it is important to note that CAP gel fabrications for human delivery have required further study due to tissue irritation in women [16]. While this irritation was determined to be due to osmolarity of the gel use of DTG-CAP-NP-Gel for female PrEP would require investigation of potential affects on vaginal $\mathrm{pH}$, micoflora, tissue irritation, and efficacy.

The known $\mathrm{pH}$ sensitivity of CAP [38] and our data at $\mathrm{pH} 7.4$ suggest that $\mathrm{pH}$ values more basic than 5.5 will lead to depolymerization of DTG-CAP-NPs. In the presence of seminal fluid, the human female vaginal environment may be neutralized along a spectrum of $\mathrm{pH}$ less basic than the normal vaginal environment and more acidic than $\mathrm{pH}$ 7.4. While examining the exact extent of depolymerization of every potential basic $\mathrm{pH}$ is beyond the scope of this initial study, these studies strongly suggest that DTG-CAP-NPs are likely to disintegrate in neutral $\mathrm{pH}$ where seminal fluid and the risk of HIV virion delivery is most likely. Further, DTG-CAP-NPs are likely to generate a sudden burst and release of DTG to provide effective protection from HIV infection. TMS gel fabrication delivers CAP's microbicidal properties and DTG's integrase inhibitor anti-HIV properties using NP design in a osmotically neutral temperature sensitive gel to potentially block both cell-free and cell-associated HIV at the vaginal epithelium. Future studies will be focused on determining the penetration properties and anti-HIV efficacy and safety of DTG-CAP-NP-Gel using both ex vivo and in vivo model systems. 


\section{Conclusions}

CAP-NPs may provide an important modality for the delivery of both microbicide function and ARV drug for female PrEP. In this study, CAP-NPs were fabricated at nanoscale, loaded with the integrase strand transfer inhibitor DTG, incorporated into thermosensitive gel, and delivered to a vaginal epithelial cell line. In vitro studies suggest that DTG-CAP-NPs can efficiently deliver both the microbicide activity of CAP and ARV activity of DTG to cells when the vaginal environment undergoes a $\mathrm{pH}$ transition associated with exposure to seminal fluid. Further studies will focus on establishing ex vivo and in vivo proofs for improved female PrEP mediated by CAP nanofabrications.

Acknowledgments: The authors would like to acknowledge Abhijit Date (+1-Daniel K. Inouye College of Pharmacy, University of Hawaii at Hilo, 200 West Kawili Street, Hilo, HI 96720) for his significant contribution to the conception of these experiments. We would like to acknowledge the Integrated Biomedical Imaging core facility at Creighton University and John Billheimer for technical expertise and assistance.

Author Contributions: Annemarie Shibata and Christopher Destache conceived the experiments; Subhra Mandal and Annemarie Shibata designed the experiments; Subhra Mandal, Rachel Pham, Karl Khandalavala, Patrick Bruck, Marisa Varghese, Andrew Kochvar, Pavan Prathipati, and Annemarie Shibata performed the experiments and analyzed data; and Annemarie Shibata, Subhra Mandal, and Karl Khandalavala composed the manuscript. All authors reviewed and provided editorial comments to the manuscript.

Conflicts of Interest: The authors declare no conflict of interest.

\section{References}

1. AIDS by the Numbers-AIDS Is Not Over, but It Can Be I UNAIDS. Available online: http:/ / www.unaids. org/en/resources/documents/2016/AIDS-by-the-numbers (accessed on 30 December 2016).

2. Doblecki-Lewis, S.; Kolber, M.A. Preventing HIV infection: Pre-exposure and postexposure prophylaxis. IUBMB Life 2014, 66, 453-461. [CrossRef] [PubMed]

3. AmfAR: Statistics: Women and HIV/AIDS: The Foundation for AIDS Research: HIV/AIDS Research. Available online: http:/ / www.amfar.org/About-HIV-and-AIDS/Facts-and-Stats/Statistics--Women-andHIV-AIDS/ (accessed on 30 December 2016).

4. Morris, G.C.; Lacey, C.J.N. Microbicides and HIV prevention: Lessons from the past, looking to the future. Curr. Opin. Infect. Dis. 2010, 23, 57-63. [CrossRef] [PubMed]

5. Adimora, A.A.; Ramirez, C.; Auerbach, J.D.; Aral, S.O.; Hodder, S.; Wingood, G.; El-Sadr, W.; Bukusi, E.A. Preventing HIV infection in women. J. Acquir. Immune Defic. Syndr. 2013, 63, S168-S173. [CrossRef] [PubMed]

6. Pirrone, V.; Wigdahl, B.; Krebs, F.C. The rise and fall of polyanionic inhibitors of the human immunodeficiency virus type 1. Antivir. Res. 2011, 90, 168-182. [CrossRef] [PubMed]

7. Destache, C.J.; Belgum, T.; Goede, M.; Shibata, A.; Belshan, M.A. Antiretroviral release from poly(DL-lactide-co-glycolide) nanoparticles in mice. J. Antimicrob. Chemother. 2010, 65, 2183-2187. [CrossRef] [PubMed]

8. Mamo, T.; Moseman, E.A.; Kolishetti, N.; Salvador-Morales, C.; Shi, J.; Kuritzkes, D.R.; Langer, R.; von Andrian, U.; Farokhzad, O.C. Emerging nanotechnology approaches for HIV/AIDS treatment and prevention. Nanomedicine 2010, 5, 269-285. [CrossRef] [PubMed]

9. Neurath, A.R.; Strick, N.; Li, Y.Y.; Lin, K.; Jiang, S. Design of a "microbicide" for prevention of sexually transmitted diseases using "inactive" pharmaceutical excipients. Biol. J. Int. Assoc. Biol. Stand. 1999, 27, 11-21. [CrossRef] [PubMed]

10. Neurath, A.R.; Strick, N.; Jiang, S.; Li, Y.-Y.; Debnath, A.K. Anti-HIV-1 activity of cellulose acetate phthalate: Synergy with soluble CD4 and induction of "dead-end" gp41 six-helix bundles. BMC Infect. Dis. 2002, 2, 6. [CrossRef]

11. Neurath, A.R.; Strick, N.; Li, Y.-Y.; Debnath, A.K. Cellulose acetate phthalate, a common pharmaceutical excipient, inactivates HIV-1 and blocks the coreceptor binding site on the virus envelope glycoprotein gp120. BMC Infect. Dis. 2001, 1, 17. [CrossRef]

12. Neurath, A.R.; Strick, N.; Li, Y.-Y. Anti-HIV-1 activity of anionic polymers: A comparative study of candidate microbicides. BMC Infect. Dis. 2002, 2, 27. [CrossRef] 
13. Manson, K.H.; Wyand, M.S.; Miller, C.; Neurath, A.R. Effect of a cellulose acetate phthalate topical cream on vaginal transmission of simian immunodeficiency virus in rhesus monkeys. Antimicrob. Agents Chemother. 2000, 44, 3199-3202. [CrossRef] [PubMed]

14. Ratterree, M.; Gettie, A.; Williams, V.; Malenbaum, S.; Neurath, A.R.; Cheng-Mayer, C.; Blanchard, J. Safety and distribution of cellulose acetate 1,2-benzenedicarboxylate (CAP), a candidate anti-HIV microbicide in rhesus macaques. AIDS 2005, 19, 1595-1599. [CrossRef] [PubMed]

15. Kim, C.N.; Adams, D.R.; Bashirian, S.; Butera, S.; Folks, T.M.; Otten, R.A. Repetitive exposures with simian/human immunodeficiency viruses: Strategy to study HIV pre-clinical interventions in non-human primates. J. Med. Primatol. 2006, 35, 210-216. [CrossRef] [PubMed]

16. Lacey, C.J.; Woodhall, S.; Qi, Z.; Sawant, S.; Cowen, M.; McCormack, S.; Jiang, S. Unacceptable side-effects associated with a hyperosmolar vaginal microbicide in a phase 1 trial. Int. J. STD AIDS 2010, 21, 714-717. [CrossRef] [PubMed]

17. Huang, C.; Soenen, S.J.; van Gulck, E.; Vanham, G.; Rejman, J.; Van Calenbergh, S.; Vervaet, C.; Coenye, T.; Verstraelen, H.; Temmerman, M.; et al. Electrospun cellulose acetate phthalate fibers for semen induced anti-HIV vaginal drug delivery. Biomaterials 2012, 33, 962-969. [CrossRef] [PubMed]

18. Blakney, A.K.; Ball, C.; Krogstad, E.A.; Woodrow, K.A. Electrospun fibers for vaginal anti-HIV drug delivery. Antivir. Res. 2013, 100, S9-S16. [CrossRef] [PubMed]

19. Date, A.A.; Shibata, A.; McMullen, E.; La Bruzzo, K.; Bruck, P.; Belshan, M.; Zhou, Y.; Destache, C.J. Thermosensitive Gel Containing Cellulose Acetate Phthalate-Efavirenz Combination Nanoparticles for Prevention of HIV-1 Infection. J. Biomed. Nanotechnol. 2015, 11, 416-427. [CrossRef] [PubMed]

20. UNAIDS Report on the Global AIDS Epidemic 2013. Available online: http://files.unaids.org/en/media / unaids / contentassets / documents / epidemiology/2013/gr2013/UNAIDS_Global_Report_2013_en.pdf (accessed on 7 April 2017).

21. Karim, Q.A.; Karim, S.S.A.; Frohlich, J.A.; Grobler, A.C.; Baxter, C.; Mansoor, L.E.; Kharsany, A.B.; Sibeko, S.; Mlisana, K.P.; Omar, Z.; et al. Effectiveness and safety of tenofovir gel, an antiretroviral microbicide, for the prevention of HIV infection in women. Science 2010, 329, 1168-1174. [CrossRef] [PubMed]

22. Serrao, E.; Odde, S.; Ramkumar, K.; Neamati, N. Raltegravir, elvitegravir, and metoogravir: The birth of "me-too" HIV-1 integrase inhibitors. Retrovirology 2009, 6, 25. [CrossRef] [PubMed]

23. Kobayashi, M.; Yoshinaga, T.; Seki, T.; Wakasa-Morimoto, C.; Brown, K.W.; Ferris, R.; Foster, S.A.; Hazen, R.J.; Miki, S.; Suyama-Kagitani, A.; et al. In Vitro antiretroviral properties of S/GSK1349572, a next-generation HIV integrase inhibitor. Antimicrob. Agents Chemother. 2011, 55, 813-821. [CrossRef] [PubMed]

24. Hightower, K.E.; Wang, R.; Deanda, F.; Johns, B.A.; Weaver, K.; Shen, Y.; Tomberlin, G.H.; Carter, H.L.; Broderick, T.; Sigethy, S.; et al. Dolutegravir (S/GSK1349572) exhibits significantly slower dissociation than raltegravir and elvitegravir from wild-type and integrase inhibitor-resistant HIV-1 integrase-DNA complexes. Antimicrob. Agents Chemother. 2011, 55, 4552-4559. [CrossRef] [PubMed]

25. Johnson, B.C.; Métifiot, M.; Pommier, Y.; Hughes, S.H. Molecular dynamics approaches estimate the binding energy of HIV-1 integrase inhibitors and correlate with in vitro activity. Antimicrob. Agents Chemother. 2012, 56, 411-419. [CrossRef] [PubMed]

26. McCormack, P.L. Dolutegravir: A review of its use in the management of HIV-1 infection in adolescents and adults. Drugs 2014, 74, 1241-1252. [CrossRef] [PubMed]

27. Fantauzzi, A.; Mezzaroma, I. Dolutegravir: Clinical efficacy and role in HIV therapy. Ther. Adv. Chronic Dis. 2014, 5, 164-177. [CrossRef] [PubMed]

28. Osterholzer, D.A.; Goldman, M. Dolutegravir: A next-generation integrase inhibitor for treatment of HIV infection. Clin. Infect. Dis. 2014, 59, 265-271. [CrossRef] [PubMed]

29. Pollicita, M.; Surdo, M.; Di Santo, F.; Cortese, M.F.; Fabeni, L.; Fedele, V.; Malet, I.; Marcelin, A.G.; Calvez, V.; Ceccherini-Silberstein, F.; et al. Comparative replication capacity of raltegravir-resistant strains and antiviral activity of the new-generation integrase inhibitor dolutegravir in human primary macrophages and lymphocytes. J. Antimicrob. Chemother. 2014, 69, 2412-2419. [CrossRef] [PubMed]

30. Underwood, M.R.; Johns, B.A.; Sato, A.; Martin, J.N.; Deeks, S.G.; Fujiwara, T. The activity of the integrase inhibitor dolutegravir against HIV-1 variants isolated from raltegravir-treated adults. J. Acquir. Immune Defic. Syndr. 2012, 61, 297-301. [CrossRef] [PubMed] 
31. Castagna, A.; Maggiolo, F.; Penco, G.; Wright, D.; Mills, A.; Grossberg, R.; Molina, J.M.; Chas, J.; Durant, J.; Moreno, S.; et al. Dolutegravir in antiretroviral-experienced patients with raltegravir- and/or elvitegravir-resistant HIV-1: 24-week results of the phase III VIKING-3 study. J. Infect. Dis. 2014, 210, 354-362. [CrossRef] [PubMed]

32. Mandal, S.; Zhou, Y.; Shibata, A.; Destache, C.J. Confocal fluorescence microscopy: An ultra-sensitive tool used to evaluate intracellular antiretroviral nano-drug delivery in HeLa cells. AIP Adv. 2015, 5, 84803. [CrossRef] [PubMed]

33. Marques, M.; Löbenberg, R.; Almukainzi, M. Simulated Biological Fluids with Possible Application in Dissolution Testing. Dissolut. Technol. 2011, 18, 15-28. [CrossRef]

34. Destache, C.J.; Mandal, S.; Yuan, Z.; Kang, G.; Date, A.A.; Lu, W.; Shibata, A.; Pham, R.; Bruck, P.; Rezich, M.; et al. Topical Tenofovir Disoproxil Fumarate Nanoparticles Prevent HIV-1 Vaginal Transmission in a Humanized Mouse Model. Antimicrob. Agents Chemother. 2016, 60, 3633-3639. [CrossRef] [PubMed]

35. Hladik, F.; Doncel, G.F. Preventing mucosal HIV transmission with topical microbicides: Challenges and opportunities. Antivir. Res. 2010, 88, S3-S9. [CrossRef] [PubMed]

36. Mandal, S.; Belshan, M.; Holec, A.; Zhou, Y.; Destache, C.J. An enhanced emtricitabine-loaded long-acting nanoformulation for prevention or treatment of HIV infection. Antimicrob. Agents Chemother. 2017, 61, e01475-16. [CrossRef] [PubMed]

37. Mandal, S.; Prathipati, P.K.; Kang, G.; Zhou, Y.; Yuan, Z.; Fan, W.; Li, Q.; Destache, C.J. Tenofovir alafenamide and elvitegravir loaded nanoparticles for long-acting prevention of HIV-1 vaginal transmission. AIDS 2017, 31, 469-476. [CrossRef] [PubMed]

38. Roxin, P.; Karlsson, A.; Singh, S.K. Characterization of cellulose acetate phthalate (CAP). Drug Dev. Ind. Pharm. 1998, 24, 1025-4101. [CrossRef] [PubMed]

39. Dezzutti, C.S.; Rohan, L.C.; Wang, L.; Uranker, K.; Shetler, C.; Cost, M.; Lynam, J.D.; Friend, D. Reformulated tenofovir gel for use as a dual compartment microbicide. J. Antimicrob. Chemother. 2012, 67, 2139-2142. [CrossRef] [PubMed]

40. Friend, D.R.; Kiser, P.F. Assessment of topical microbicides to prevent HIV-1 transmission: Concepts, testing, lessons learned. Antivir. Res. 2013, 99, 391-400. [CrossRef] [PubMed]

41. Catalone, B.J.; Kish-Catalone, T.M.; Budgeon, L.R.; Neely, E.B.; Ferguson, M.; Krebs, F.C.; Howett, M.K.; Labib, M.; Rando, R.; Wigdahl, B. Mouse model of cervicovaginal toxicity and inflammation for preclinical evaluation of topical vaginal microbicides. Antimicrob. Agents Chemother. 2004, 48, 1837-1847. [CrossRef] [PubMed]

42. Fonte, P.; Soares, S.; Costa, A.; Andrade, J.C.; Seabra, V.; Reis, S.; Sarmento, B. Effect of cryoprotectants on the porosity and stability of insulin-loaded PLGA nanoparticles after freeze-drying. Biomatter 2012, 2, 329-339. [CrossRef] [PubMed]

(C) 2017 by the authors. Licensee MDPI, Basel, Switzerland. This article is an open access article distributed under the terms and conditions of the Creative Commons Attribution (CC BY) license (http://creativecommons.org/licenses/by/4.0/). 